\title{
Tomás de Aquino e o Problema das Ideias Divinas de Coisas Singulares
}

\author{
Antoine Côté \\ coteaj@uottawa.ca \\ University of Ottawa, Ottawa, Canadá \\ Eduardo Zachia \\ eduisdra@hotmail.com \\ University of Ottawa, Ottawa, Canadá \\ resumo Este artigo analisa diversos textos da obra de Tomás de Aquino relativos aos \\ temas do conhecimento divino e das ideias divinas com o intuito de mostrar como duas \\ interpretações sustentadas por comentadores recentes da obra tomásica não se mantêm \\ diante da análise rigorosa dos textos. Uma primeira e menos radical interpretação \\ sustenta haver ideias práticas distintas de cada coisa particular, enquanto que, de \\ acordo com uma interpretação ainda mais forte, ideias em sentido estrito pertencem \\ primordialmente a coisas singulares. 0 objetivo deste artigo é mostrar que, embora \\ Tomás sustente que Deus conhece todas as coisas, inclusive os particulares, a doutrina \\ das ideias, tal como Tomás a concebe, tem limites muito estreitos, não permitindo 0 \\ pleno desenvolvimento de suas convicções de cunho aristotélico concernentes à \\ cognoscibilidade dos particulares.
}

palavras-chave ideias; particulares/singulares; espécie; conhecimento divino; aristotelismo; platonismo

Desde o início de sua carreira como teólogo, Tomás de Aquino nunca deixou de sustentar que Deus possui ideias de todas as coisas. O que dizer, em especial, acerca das coisas singulares? ${ }^{1}$ Tomás afirma de maneira firme e constante que Deus conhece o singular, não resta dúvida, mas quer isto dizer que ele possui também as ideias das coisas singulares? Dito de outro modo, há, segundo Tomás, uma ideia relativa a cada coisa conhecida? Isto é o que Tomás parece indicar em diversas passagens (De Veritate, q. 3, a. 8, c; Summa Theologiae I, q. 15, a. 3, ad 4), mas sem fornecer maiores detalhes. $\mathrm{O}$ fornecimento destes detalhes fica ao encargo dos Recebido em 13 de dezembro de 2009. Aceito em 18 de fevereiro de 2010. Tradução: Marina dos Santos - UFRGS doispontos, Curitiba, São Carlos, vol. 7, n. 1, p.41-68, abril, 2010 
comentadores da obra tomásica, os quais se baseiam nas passagens em que Tomás trata do modo pelo qual Deus conhece as criaturas. Segundo o Aquinate, com efeito, Deus possui um conhecimento das criaturas; ora, a ideia é a forma do conhecimento prático (Super Sent., lib. 1, d. 36, q. 2, a. $1, \mathrm{c})$, e, como Tomás afirma que Deus possui ideias de tudo aquilo que ele cria $(D V$, q. 2, a. 8, ad. 3), segue-se que ele possui ideias práticas de coisas particulares, pois são estas últimas que são objeto de seu ato criacional, havendo, assim, uma ideia distinta para cada coisa particular (Contra Gentiles, I, 65, n. 3). ${ }^{2}$ Outros comentadores vão ainda mais longe, sustentando não apenas que Deus possui ideias de singulares, mas que as ideias divinas, segundo Tomás, seriam, primeira e fundamentalmente, ideias de particulares; e, por consequência, que ideias de espécies não são ideias senão num sentido secundário. Tal posição, de acordo com os mesmos comentadores, não seria apenas mais uma tese em meio a tantas outras que caracterizam a teologia tomásica, mas antes algo que apontaria para um aspecto central de sua doutrina, a saber, a sua crença na "radical inteligibilidade do real"', a qual seria, ela mesma, a expressão de uma clara preferência por uma ontologia aristotélica ${ }^{4}$, em detrimento de uma outra, de cunho platônico. ${ }^{5}$

Sem querer contestar a posição de acordo com a qual Tomás aceita a tese da inteligibilidade do real como um todo, nem, tampouco, que ele atribua a Deus um conhecimento do singular, pois isto é incontestável, nós gostaríamos simplesmente de mostrar aqui como as duas teses que acabamos de resumir - aquela segundo a qual Tomás defende que Deus possui ideias distintas de coisas singulares e também aquela de acordo com a qual Tomás sustenta que ideias são primeiramente ideias de particulares - dificilmente harmonizam com a maioria dos textos onde Tomás trata ex professo do tema das ideias divinas e de modo algum com um único texto, em Quaetiones Quodlibetales 8, q. 1, a.2, no qual a questão se as ideias divinas se referem primeiramente a coisas particulares é tratada de maneira direta.

Antes de começar, seria importante distinguir cuidadosamente dois contextos precisos em que Tomás trata do conhecimento divino de singulares ${ }^{6}$. O primeiro contexto é relativo à polêmica anti-aviceniana e anti-averroista concernente ao conhecimento divino dos particulares. Estes são os textos em que Tomás se pronuncia mais categoricamente a 
favor da tese do conhecimento divino de singulares. O segundo contexto, mais antigo, mais convencional, refere-se à doutrina das Ideias, a qual Tomás associa ao nome de Platão, e que ele reconstitui com a ajuda de elementos resgatados principalmente em Aristóteles e Santo Agostinho. Ali, sua resposta à questão se Deus possui ideias de singulares é menos clara. Nós começaremos evocando o primeiro contexto, passando, em seguida, a uma análise mais pormenorizada dos textos tomásicos relativos ao segundo contexto.

\section{Deus tem conhecimento dos singulares}

Seja no Scriptum super Sententiis, ou nas Questões Disputadas, ou mesmo na Suma Teológica7, é sob o pano de fundo das teses de Avicena e de Averróis que Tomás aborda o problema do conhecimento divino de singulares. Contra estes dois filósofos, os quais, em nome da transcendência e perfeição divinas, buscam negar o conhecimento divino acerca de particulares, Tomás responde de maneira categórica que a ciência divina engloba a totalidade dos entes criados.

Mais especificamente, Tomás se insurge contra três teses: 1) a tese que nega a Deus qualquer conhecimento do particular; 2) a tese segundo a qual atribui-se a Deus um conhecimento do singular mediado por causas universais; e 3) a tese de acordo com a qual Deus conhece os singulares por intermédio da aplicação de causas universais a efeitos particulares. A estas três teses, Tomás contrapõe a firme defesa da seguinte posição: se Deus é causa de todas as criaturas, bem como de seus princípios constitutivos, cabe a ele conhecê-las todas, inclusive no que diz respeito à sua materialidade.

Antes de expor sua posição, Tomás começa por oferecer o diagnóstico do erro subjacente às três teses de seus adversários. A doutrina errônea acerca do conhecimento divino defendida pelos filósofos árabes é, com efeito, tributária de uma concepção - segundo Tomás, também errônea a respeito da causalidade divina. Na medida em que Deus, segundo estes mesmos autores árabes, não é causa do particular senão através da mediação de causas superiores ao singular, segue-se que Deus não pode conhecer o particular senão por meio destas mesmas causas superiores. 


\section{4}

Ora, a tese de Tomás é justamente que Deus é causa operante de todas as coisas; daí se segue que ele deve conhecê-las todas (cf. $S_{c} G, \mathrm{I}, 65, \mathrm{n}$. 2). E é na medida em que o modo do conhecer é função do modo da causalidade que Tomás julga necessário, a fim de delimitar a relação epistêmica que Deus entretém com as coisas criadas, representar esta mesma relação segundo a analogia do conhecimento prático que possui o artesão daquilo que ele deseja construir, e não segundo a analogia do conhecimento teórico, resultante da ação das coisas elas mesmas sobre o intelecto. É certo que o construtor, conhecendo a forma geral da casa a ser construída, não conhece a casa concreta, aquela que sua ciência lhe permite construir, exceto por meio de um ato perceptivo ensejado pela própria construção, quer dizer, na medida em que esta última é capaz de agir sobre suas faculdades sensoriais. No entanto, se aquela forma geral existente no intelecto do construtor fosse igualmente responsável pela geração da matéria, o construtor conheceria, de uma só vez, a natureza universal da casa bem como as casas individuais. $\mathrm{O}$ mesmo se aplica à natureza divina: causa total da forma e da matéria enquanto criador, Deus possui um conhecimento que inclui de uma só vez naturezas universais e coisas singulares. ${ }^{8}$

A orientação do que acabamos de chamar de "relação epistêmica" é, portanto, inversa no caso de Deus: ela não vai das coisas ao intelecto, mas do intelecto às coisas. E porque o intelecto em questão é o intelecto de um ser criador, ele conhece os entes na exata medida em que os cria. É esta doutrina que permite Tomás responder a uma objeção à primeira vista temível. Segundo um “axioma" metafísico bastante conhecido, tudo o que é recebido é recebido segundo o modo do recebedor. É justamente em razão disso que o intelecto humano não conhece o singular na sua singularidade. Com que direito, então, conferir a Deus um tal conhecimento, já que se supõe que o intelecto divino seja imaterial? Para responder a esta objeção, explica Tomás, convém apreender os diferentes modos pelos quais uma similitude se refere às coisas, de acordo com a sua presença no intelecto divino ou no intelecto humano. No homem, a similitude é decorrente das coisas, enquanto que em Deus ela é produtora das coisas. ${ }^{9}$

Ao examinarmos as conclusões enunciadas por Tomás de Aquino nas passagens onde ele trata do conhecimento divino do singular, nos 
deparamos ao mesmo tempo com o tom categórico de suas conclusões e com a firmeza da base teórica sobre a qual elas repousam: Deus conhece o particular pois a modalidade do seu conhecimento das coisas é função da sua natureza enquanto criador. No entanto, como veremos a seguir, o panorama se altera nos textos em que Tomás trata das ideias divinas. Nós iremos passar em revista as quatro principais exposições que Tomás consagra a este tema - são elas: Scriptum super Sententiis, I, dist. 36, q. 2, a. 3; De veritate, q. 3, a. 8; Contra Gentiles I, 54 e Summa Theologiae I, q. 15, a. 3. Para tanto, faremos uso das diferentes interpretações que foram sugeridas pelos partidários das duas teses às quais fizemos menção em nossa introdução.

\section{Possui Deus as ideias das coisas particulares enquanto particulares?}

\section{a) Scriptum super Sententiis}

No Comentário sobre as Sentenças, dist. 36, q. 2, a. 3, encontramos uma primeira reflexão acerca do tema das ideias divinas. Ali, Tomás pergunta se há em Deus ideias referentes a tudo aquilo que é objeto do conhecimento divino. Sua resposta é que uma ideia é a similitude de algo em Deus na medida em que tal ideia é produtora da coisa em questão. Tudo o que é produzido por Deus deve, portanto, possuir uma ideia em Deus; e, como tudo é produzido por Deus, segue-se que deve haver em Deus uma ideia distinta para cada coisa existente:

Respondeo dicendum, quod, sicut ex auctoritate Dionysii inducta patet, idea dicitur similitudo vel ratio rei in Deo existens, secundum quod est productiva ipsius rei et determinativa; et ideo unumquodque, secundum quod se habet ad hoc quod a Deo producatur, ita se habet ad hoc quod ipsius idea sit in eo. Omne autem quod ab aliquo per se agente producitur, oportet quod secundum hoc quod ab ipso effectu est, ipsum imitetur; quia, ut probat philosophus, simile agit sibi simile, tam in his quae agunt per voluntatem quam in his quae agunt per necessitatem. Unde secundum id quod aliquid a Deo producitur, secundum hoc similitudinem in ipso habet, et secundum hoc est idea ipsius in Deo, et secundum hoc a Deo cognoscitur; et ideo cum omnis res a Deo producatur, oportet omnium rerum ideas in ipso esse $e^{10}$. 
Tomás, no entanto, deve imediatamente responder a uma objeção interessante: Deus não conhece apenas os universais, mas também o particular; ora, admitindo-se que a ideia de algo nada mais é do que a ideia de sua espécie, não parece que possa haver em Deus ideias de coisas particulares, já que esta última em nada distinguir-se-ia da ideia referente à espécie.

A esta objeção, Tomás responde não apenas que Deus tem ciência dos particulares, mas que ele os conhece em virtude de uma ideia que lhes é própria: "a noção [ratio] de Pedro é outra que aquela de Martinho, como a de homem é distinta da de cavalo". Deve, portanto, haver em Deus uma ideia de Pedro que seja distinta daquela de Martinho. O ponto parece claro, no entanto Tomás adiciona uma importante precisão, cujo significado é um pouco confuso, mas que parece, de todo modo, limitar significativamente o impacto de sua resposta inicial. Pois há uma diferença importante, explica ele, entre a maneira pela qual "homem" se distingue de "cavalo" e aquela pela qual Pedro se distingue de Martinho. A primeira é uma distinção segundo a forma, à qual a ideia responde de maneira perfeita; já a segunda é uma distinção segundo a matéria, à qual a ideia responde de maneira imperfeita.

Ad tertium dicendum, quod particularia habent proprias ideas in Deo; unde alia est ratio Petri et Martini in Deo, sicut alia ratio hominis et equi. Sed tamen diversitas hominis et equi est secundum formam, cui perfecte respondet idea: sed distinctio singularium unius speciei essentialis, est secundum materiam, quae non perfecte habet ideam; et ideo perfectior est distinctio rationum respondentium diversis speciebus quam diversis individuis; ita tamen quod imperfectio referatur ad res imitantes, et non ad essentiam divinam quam imitantur ${ }^{11}$.

É preciso notar que Tomás não diz que a ideia de uma coisa singular é ela mesma imperfeita - o que significaria atribuir uma imperfeição a Deus. O que é dito é que uma ideia responde de modo imperfeito ao singular. Mas será que uma e outra dizem mesmo coisas diferentes? É algo que pode ser posto em questão. Prova disso é que Tomás se apressa em proteger-se desta mesma objeção, sustentando que a imperfeição da correspondência entre coisa e ideia é antes atribuível às coisas elas mesmas do que à essência divina, a qual elas imitam. No entanto, é possível que nos interroguemos sobre o valor desta explicação. Pois a partir do momento 
em que se reconhece que a relação de correspondência entre duas coisas é imperfeita, qual a importância de saber sobre qual dos dois membros recai a imperfeição? ${ }^{12}$ Dizer que a ideia responde imperfeitamente à diversidade segundo a matéria não significa dizer que a ideia não é um instrumento adequado à apreensão do singular enquanto tal?

\section{b) De Veritate}

A questão de saber se há em Deus ideias de coisas particulares é objeto explícito da terceira questão, artigo oitavo, do De Veritate. No respondeo deste artigo, Tomás expõe dois argumentos buscados em Platão e Aristóteles, os quais parecem estabelecer oposição à admissão do princípio segundo o qual Deus possui ideias de particulares.Vejamos o primeiro argumento: ideias, segundo Platão, não são responsáveis pela produção da matéria, mas apenas da forma; ora, é a matéria que é princípio de singularidade. Segundo argumento: não há ideia senão daquilo que por si constitui o objeto de uma intenção; ora, na natureza, é a conservação da espécie que é intencionada: embora seja este homem o responsável pela geração daquele outro homem, o que é visado em primeiro lugar é homem enquanto espécie. É por esta mesma razão que Platão negou-se a admitir ideias relativas a gêneros. Quanto ao ponto acima descrito, Aristóteles parece concordar com seu mestre. Causas finais são necessárias para explicar acidentes específicos, mas não para dar conta dos acidentes individuais, os quais requerem apenas causas eficientes e materiais.

Tendo exposto o dossiê em questão, Tomás, como já havia sido feito no texto de Sobre as Sentenças, conclui sua resposta com um enunciado breve e claro de sua posição pessoal: "Afirmamos que Deus é causa do singular tanto do ponto de vista de sua forma quanto de sua matéria. Afirmamos igualmente que as coisas singulares são definidas pela providência divina; segue-se, portanto, que sustentamos haver ideias de coisas singulares". ${ }^{13}$

Ao afirmar que há ideias de coisas singulares estaria Tomás a dizer que ideias são exclusivamente de coisas singulares? Sua resposta nos inclina a pensar que não: "Sustentamos ser Deus a causa do singular tanto no que respeita à forma quanto no que respeita à matéria". No entanto, para conhecermos o fundamento de sua posição quanto ao presente ponto é preciso atentar para a sua resposta à segunda objeção. À primeira vista, a 
objeção é boa: suponhamos haver em Deus uma ideia relativa a singulares; ou bem a ideia do singular é a mesma que a ideia de sua espécie, ou bem ela é diferente. Se idêntica for, significará haver uma só ideia comum a todos os particulares pertencentes a uma mesma espécie. Se diferentes, seguir-se-á que uma mesma coisa possui, em Deus, duas ideias distintas. Em sua resposta, Tomás distingue dois sentidos do termo "ideia": ideia num sentido próprio e ideia num sentido corrente. No seu sentido próprio, uma ideia é ideia de uma coisa (rei) enquanto realmente produtível: neste sentido, ela corresponde tanto ao singular, quanto à espécie, ou até mesmo o gênero. Em contrapartida, em seu sentido corrente, dir-se-á haver diversas ideias de Sócrates, na medida em que podemos distinguir Sócrates enquanto um particular, enquanto homem, ou enquanto animal. Não há diferença, do ponto de vista do ser de Sócrates, entre Sócrates o indivíduo, a espécie ou o gênero. Sócrates é realmente um homem, bem como realmente um animal. Mais uma vez, longe de dizer que a ideia divina correspondente a Sócrates nada mais é do que a ideia de Sócrates-indivíduo, Tomás afirma com clareza a convergência das três numa única e mesma coisa (res). ${ }^{14}$

Curiosamente, alguns intérpretes recentes veem neste artigo do De Veritate a mais clara afirmação por parte de Tomás em favor da tese que as ideias divinas são ditas, em sentido próprio, de indivíduos. Tal conclusão impor-se-ia, assim nos é dito, sob a condição de que se leia este artigo à luz dos quatro tipos de conhecimento distinguidos em De Ver., q. 3, a. 3. Neste texto, Tomás explica que Deus possui (1) um conhecimento prático das coisas que ele cria; (2) um conhecimento virtualmente prático no que concerne às coisas que ele é capaz de criar mas que de fato não cria; (3) um conhecimento especulativo acerca daquilo que ele é incapaz de criar, os impossibilia, e também do mal; (4) por último, Deus igualmente possui um conhecimento especulativo acerca das notas distintivas dos seres que ele cria, mas as quais não são capazes de existir separadamente. Na medida em que as ideias divinas, segundo a definição dada por Tomás, são produtoras dos seres, segue-se que elas caracterizam um conhecimento prático. A conclusão extraída por Doolan é a seguinte: "Since ideas in the strict sense do belong to practical knowledge, there are properly speaking only ideas of individuals because only individuals can actually be produced"15. No entanto, como acabamos de ver, o que é dito por Tomás em De Ver., q. 3, 
a. 8, ad. 2 é exatamente o contrário do que é defendido por Doolan: "dicendum, quod si loquamur de idea proprie, secundum quod est rei, eo modo quo est in esse producibilis; sic una idea respondet singulari, speciei, et generi, individuatis in ipso singulari, eo quod Socrates, homo et animal non distinguuntur secundum esse" 16 . Consciente de que nem o respondeo nem as respostas às objeções vão no mesmo sentido de sua interpretação pessoal, Doolan vêse obrigado a invocar o segundo sed contra do mesmo artigo, no qual lêse o seguinte:

"Ideias são ordenadas à existência das coisas. Os singulares, no entanto, têm ser mais verdadeiramente do que os universais, já que estes últimos não subsistem senão nos singulares. Donde, os singulares requerem ideias mais do que os universais". ${ }^{17}$

Doolan fala do texto acima como se este exprimisse uma sugestão de Tomás de Aquino. No entanto, algumas páginas adiante, ao trazê-lo à baila novamente, a "sugestão" transforma-se em "explicação": "As he explains in the De veritate, individual things have being (esse) more truly than do universals, for universals subsist only in individuals. As a result, individuals have a greater need for ideas" 18 . Na verdade, não resta dúvida acerca de qual conclusão se impõe: assim como no texto de Sobre as Sentenças, ainda que por razões distintas, Tomás não afirma no De Veritate que as ideias divinas são primeiramente ideias de indivíduos.

\section{c) Summa Contra Gentiles}

Passemos, agora, ao texto da Suma Contra Gentios, obra que ocupa um lugar à parte na historiografia tomásica referente às ideias divinas, já que nela Tomás não faz uso do termo "ideia” para expressar sua doutrina, fato que levou alguns a crer que Tomás não trata nesta obra do tema das ideias divinas. Lembremos um pouco dos fatos. Sabemos que uma parte importante do autógrafo de Contra Gentiles foi conservada, e em particular a totalidade dos capítulos referentes ao tema das ideias divinas no livro I. ${ }^{19}$ Alguns destes capítulos foram objeto de diversas alterações. Este é o caso de I, 53, o qual foi alvo de três sucessivas redações ${ }^{20}$, mas também de I, 54, o qual trata de como pode a similitude que é o Verbo divino ser a similitude própria a uma multiplicidade de coisas. O capítulo 54, por sua vez, passou por duas redações, sendo que a final é sensivelmente mais enxuta 
do que a primeira, descartada por Tomás. ${ }^{21} \mathrm{~A}$ primeira redação termina com uma longa passagem na qual Tomás busca mostrar em que sentido a doutrina platônica das Ideias pode concordar com o ensinamento tradicional dos doutores cristãos e do Evangelho: Platão pressentiu a verdade, afirma Tomás, mas apenas de longe.

Podemos, aqui, fazer menção a dois pontos. Em primeiro lugar, as poucas ocorrências do termo "idea", que foram suprimidas quando da segunda redação de I, 54, não se encontravam nas partes do texto em que Tomás expunha sua própria doutrina. Tal constatação, por si só, assim pensamos, deveria atenuar o peso que alguns atribuem à correção feita por Tomás. ${ }^{22}$ Em todo caso, parece arriscado concluir, como alguns quiseram fazer, que as referidas supressões expressam uma radical alteração doutrinal por parte de Tomás. Mais do que isso, elas parecem expressar uma desconfiança em relação a Platão.

Em segundo lugar, gostaríamos de mencionar que, se é verdade que Tomás não faz uso do termo "ideia" em I, 54, isto não impede que o conceito veiculado pelo termo esteja, ele mesmo, bastante presente, e que os problemas abordados por Tomás em I, 54 sejam os mesmos que aqueles examinados em textos paralelos, onde, como vimos naqueles aqui estudados, Tomás faz uso do termo "ideia". O que realmente muda é que, ao invés de falar em ideias, Tomás emprega o termo "rationes". Como escreve L.-B. Geiger, "muito embora sejam as ideias nomeadas apenas incidentalmente no nosso capítulo 53, é exatamente do problema posto por elas que se trata, bem como da resposta elaborada por Santo Tomás no intuito de fornecer-lhe uma resposta"23. O mesmo comentário se aplica a I, 54. No mais, como Tomás ele mesmo explica, uma ideia pode ser considerada sob dois pontos de vista: 1) sob o aspecto da causalidade exemplar que ela representa, e assim ela é dita "forma"; 2) sob o aspecto da coisa da qual ele é ideia - e assim a chamamos "ratio" 24 .

$\mathrm{Na}$ medida em que I, 54 fornece uma resposta a um problema enunciado em I, 50 - que Deus tem um conhecimento próprio de todas as coisas - é preciso tratar este conjunto de capítulos como expressando uma unidade. É fundamental compreender, no que diz respeito a I, 50, que quando Tomás pergunta se Deus possui um conhecimento de todas as coisas (omnium rerum), ele não está a indagar "Deus conhece cada coisa na sua individualidade de coisa singular?", mas antes "Deus conhece cada 
coisa de acordo com a natureza desta?”. E o que Tomás irá estabelecer num primeiro momento é que Deus possui um conhecimento da natureza de todas as coisas que ele cria. Em seguida, ele mostra como isto pode ser o caso, sustentando que Deus, em virtude de sua própria essência una, é uma similitude de todas as coisas (c. 53), para, enfim, provar (c. 54) que uma e a mesma essência pode, sem risco de contradição, ser a similitude de uma pluralidade de coisas. É importante ressaltar que toda a discussão se dá no plano das essências ou "naturezas" das coisas.

Diversas passagens, do capítulo 50 em diante, confirmam o que foi dito acima. Assim, Tomás formula da seguinte maneira o objeto de investigação do capítulo: “É preciso mostrar que Deus conhece todas as outras coisas como sendo distintas dele e entre si. Isto implica conhecer as coisas segundo suas próprias naturezas" 25 . Dentre as diversas provas das quais Tomás lança mão neste mesmo capítulo, poderíamos ressaltar três, que põem em evidência este mesmo fato. Uma primeira se extrai de uma propriedade que Tomás atribui a toda causa inteligente, a saber, ter conhecimento acerca daquilo que produz. Deus necessariamente conhece aquilo que ele cria, na medida em que "tudo aquilo que age intelectualmente possui um conhecimento daquilo que produz segundo a natureza própria à coisa produzida" 26 .

A mesma conclusão é extraída da tese geral segundo a qual aquele que conhece uma coisa, conhece tudo o que ela contém. Em função de Deus possuir um conhecimento perfeito de sua essência, segue-se que ele deve possuir um conhecimento perfeito de sua potência ativa. Segue-se, portanto, que ele possui um conhecimento próprio de todas as coisas, já que "todas as coisas, segundo suas formas próprias, estão em Deus de acordo com a sua potência ativa, visto que ele é princípio de cada ente" 27.

Enfim, Deus conhece todas as maneiras pelas quais ele pode ser imitado. Ora, tais diferentes maneiras nada mais são do que formas naturais. A este propósito, Tomás lembra que Aristóteles chama a forma natural de "algo divino". Deus, por conseguinte, conhece as coisas de acordo com sua formas próprias. ${ }^{28}$

A dificuldade filosófica que é levantada pela doutrina segundo a qual Deus conhece as coisas de acordo com suas formas próprias diz respeito à natureza mesma destas coisas enquanto presentes no intelecto divino: 


\section{2}

fazem elas parte da essência divina? Aderem-se elas à essência divina sob a forma de acidentes? A resposta do Aquinate, de natureza negativa, se desenvolve em dois tempos. O primeiro corresponde ao capítulo 53: a partir de uma análise do conhecimento humano, o qual se dá mediante a produção de certas noções que se referem às coisas como suas similitudes, Tomás conclui que o modo de compreensão próprio à essência divina também é segundo uma similitude, com a diferença que ela é similitude de todas as coisas. Mostrar como tal doutrina é possível é o objetivo do capítulo 54, segundo momento da análise tomásica. Antes de examinar em detalhe a argumentação do Aquinate neste capítulo, convém por em relevo as particularidades e implicações do processo adotado no capítulo 53. Com efeito, é a partir de considerações relativas às condições do conhecimento humano que Tomás diz poder explicar como uma pluralidade de rationes pode existir em Deus sem, com isso, constituir uma real multiplicidade. $\mathrm{O}$ intelecto humano, como explica Tomás, é caracterizado pela sua capacidade de "pensar a coisa como separada de suas condições materiais, sem as quais ela não existe na realidade; mas isso não poderia ocorrer se o intelecto não formasse para si uma noção [intentionis]" (53,3). É sobre este ponto - a capacidade de formar para si uma noção, que é exatamente o que significa pensar algo - que se vai construir a analogia entre os intelectos humano e divino, pondo-se à parte duas diferenças importantes: em primeiro lugar, a essência divina não é exatamente produtora de uma noção; antes, enquanto Verbo, ela própria é uma tal noção. Em segundo lugar, como já referimos, a essência divina é noção de todas as coisas, e não apenas de uma: "Segue-se, portanto, que a concepção própria ao intelecto divino, enquanto pensamento de si mesmo, concepção essa que é o verbo, não é apenas uma similitude de Deus ele mesmo enquanto pensado, mas antes de todas as coisas das quais a essência divina é uma similitude. Deste modo, mediante uma só espécie inteligível, isto é, a essência divina, e mediante a compreensão de uma só noção, a saber, o verbo divino, uma multiplicidade de coisas pode ser pensada por Deus"29. Mais uma vez, o importante aqui é compreender que as noções das quais Tomás trata são de fato noções de coisas singulares, porém não enquanto singulares, mas sim enquanto universais - assim como a ideia de homem é tanto ideia de Martinho quanto de Pedro. 
Resta ainda estabelecer um último ponto: como pode a similitude que é oVerbo divino ser a similitude própria de uma multiplicidade de coisas? É exatamente isso que Tomás busca provar no capítulo 54, cuja análise demandará, aqui, um bom espaço. Neste momento, o que devemos destacar é justamente o termo "próprio". O problema técnico apontado por Tomás consiste em saber se uma noção pode ser a similitude própria a uma multiplicidade - própria, e não comum. Pois não há nenhuma dificuldade em conceber como uma noção pode ser a similitude comum a uma multiplicidade de coisas. Deste modo, tomando o exemplo de Tomás, "animal" é uma similitude comum a todas as espécies animais. $\mathrm{O}$ que se quer saber é como pode Deus ser a similitude única e própria de uma multiplicidade de coisas distintas entre si. Como sustenta Tomás numa passagem a qual teremos oportunidade de voltar: "se Deus possui um conhecimento próprio de uma pluralidade de coisas, é preciso que ele seja, ele mesmo, a noção própria de cada uma delas"30. A solução é operada em dois momentos: Tomás começa por mostrar que é possível conceber, na ordem das coisas criadas, como uma só noção pode ser uma similitude própria a uma multiplicidade de coisas, para, em seguida, transpor esta conclusão ao caso de Deus. Na primeira etapa de seu argumento, ele se baseia na diferença que se observa na propriedade das formas segundo a ordem a partir da qual elas se encarnam. Deste modo, na ordem natural das coisas, uma modificação ocorrente no plano das formas, como a extração ou adição de uma diferença, traduz-se em termos de uma diferença real: a diferença "racional", adicionada à substância "sensível", produz um ser - homem - distinto das diferentes espécies de seres dotados de sensibilidade. Quanto a este aspecto, explica Tomás, retornando a Metafísica de Aristóteles, formas assemelham-se a números: a adição ou subtração de uma unidade a um número gera um novo número. Já na ordem do pensamento, as coisas se dão diferentemente. $\mathrm{O}$ intelecto pode considerar isoladamente a seu bel-prazer elementos que não são realmente distintos, por exemplo, "no número três, pode considerar apenas o dois, e em animal racional, apenas aquilo que é sensível" 31 . Tomás vai ainda mais longe: o intelecto pode considerar como constituindo a razão própria de uma dada multiplicidade a razão correspondente a uma multiplicidade mais ampla. Ele pode, por exemplo, considerar o 10 como razão própria do 9, subtraindo daquele, 


\section{4}

em pensamento, uma unidade. Tomás, em seguida, cita um exemplo revelador e ainda mais pertinente, pois não implica nenhuma diferença no que concerne ao particular: "É também desta maneira que ele [intelecto] pode apreender em "homem" o exemplar próprio de "animal irracional" enquanto tal, e de suas diferentes espécies, a menos que essas adicionem certas diferenças positivas" 32 .

Não é difícil transpor este resultado para o caso de Deus. Na medida em que os entes criados são, para Tomás, imitações do ser divino, a compreensão que Deus tem de cada criatura é uma compreensão da maneira segundo a qual cada um destes entes imita a essência divina. Criaturas distintas, encarnando perfeições de naturezas diferentes, imitam diferentemente uma e a mesma essência divina. Assim, não é preciso que Deus possua as diversas ideias ou noções para que possa ter um conhecimento próprio das perfeições criadas correspondentes. É através do conhecimento de sua única e mesma essência que ele possui um conhecimento próprio de cada uma delas. Em suma, o que a argumentação de Tomás visa a mostrar é que a diferença entre os intelectos divino e humano, do ponto de vista do conhecimento de uma multiplicidade de objetos, é uma diferença que se explica em termos de intensidade e pujança: não é o caso de se negar ao homem aquilo que se atribui a Deus, a saber, a capacidade de pensar distintamente (proprie) os elementos de um todo a partir da concepção do todo. Pelo contrário, o intelecto humano pode apreender as noções próprias de certas perfeições através de uma apreensão única de uma ideia mais geral é este o testemunho dado pelos exemplos citados acima. O que lhe é negado, por sua vez, é a apreensão de todas as perfeições criadas por meio de uma só ideia. Esta última é prerrogativa de Deus.

Há, portanto, uma perfeita unidade de propósito no grupo de capítulos 50-54. Toda a análise se situa, por assim dizer, no plano das essências puras. Nenhuma menção explícita é feita ao particular.

No entanto, tão logo nos reportamos aos principais comentários ao capítulo 54, constatamos não sem surpresa que estes extraem do texto tomásico uma lição bem mais forte do que aquela que até aqui estivemos a desenvolver.V. Boland, por exemplo, assim escreve: "God knows general qualities like life, knowledge and understanding, but he also knows individuals and comprehends what is essentially proper to each thing. He understands how each thing imitates the divine essence and how it falls short of the perfection of the 
divine essence. Therefore: essentia divina, inquantum est absolute perfecta, potest accipi ut propria ratio singulorum" 33 .

Seguindo pela mesma esteira, G. Doolan, analisando a mesma passagem, sustenta que "since the divine essence is absolutely perfect, it can be viewed as the proper notion even of individual things. In this way, God can have the proper knowledge of all things" 34 .

Como dar conta de uma tal divergência? A chave para a resposta se encontra no termo singulus, o qual é usado pelo Aquinate quatro vezes no capítulo 54. Trata-se de um adjetivo distributivo cujo significado pode ser expresso pela locução "um a um". Sua presença se explica sem maiores problemas no contexto do nosso capítulo, visto que Tomás busca dar conta da diferença entre um conhecimento comum (aplicável a um conjunto de coisas) e um conhecimento próprio (referente aos membros do conjunto) - isto é, um conhecimento capaz de apreender "disjuntivamente" aquilo que existe de um modo "conjuntivo" "Intellectus vero ea quae sunt in esse coniuncta, interdum disunctim accipere potest..." [SCG I 54, n. $3]$ ). Tomás emprega, no capítulo 54 , o termo singulus quatro vezes, todas elas no genitivo plural. Passemos às ocorrências:

1) Oportet igitur, si Deus de pluribus propriam cognitionem habet, quod ipse sit propria ratio singulorum.

2) Potest enim accipere denarium ut propriam rationem novenarii, una unitate subtracta; et similiter ut propriam rationem singulorum numerorum infra inclusorum.

3) Similiter etiam in homine accipere potest proprium exemplar animalis irrationalis inquantum huiusmodi, et singularum specierum eius, nisi aliquas differentias adderent positivas.

4) Intellectus igitur divinus id quod est proprium unicuique in essentia sua comprehendere potest, intelligendo in quo eius essentiam imitetur, et in quo ab eius perfectione deficit unumquodque: utpote, intelligendo essentiam suam ut imitabilem per modum vitae et non cognitionis, accipit propriam formam plantae; si vero ut imitabilem per modum cognitionis et non intellectus, propriam formam animalis; et sic de aliis. Sic igitur patet quod essentia divina, inquantum est absolute perfecta, potest accipi ut propria ratio singulorum.

O fundamental aqui é não confundir o adjetivo distributivo singulus com o adjetivo substantivado singulare, o qual, por sua vez, tem o sentido de "singular" ou "coisa singular" ou, ainda, "coisa particular", mas que Tomás não emprega no referido capítulo. Por outro lado, em outros 
contextos, Tomás faz uso da expressão ratio singularium, como veremos um pouco mais adiante. Esta última de fato significa "uma noção de coisas singulares". Ao nos reportarmos às traduções de singularum/singulorum em cada uma das passagens que acabamos de reproduzir, constatamos que a maioria dos tradutores confere à expressão o sentido errado de "singular" ou "coisa singular". Damos aqui uma amostra destas traduções equivocadas, em três línguas européias.

Tradução francesa de Michon

1) Si Dieu a une connaissance propre de plusieurs choses, il faut donc qu'il soit lui-même la notion propre des singuliers.

2) Il peut saisir le dix comme la notion propre du neuf,en soustrayant une unité; et de la même manière comme la notion propre des différents nombres qu'il renferme.

3) C'est aussi de cette manière qu'il peut saisir dans l'homme le type propre de l'animal irrationnel en tant que tel, et de ses différentes espèces, sauf si celles-ci ajoutaient des différences positives.

4) Il est donc manifeste que l'essence divine, dans la mesure où elle est absolument parfaite, peut être considérée comme la notion propre des singuliers.

Tradução inglesa de Pegis

1) Therefore, if God has a proper knowledge of many things, He must be the proper model of singulars.

2) It can, for example, take the number ten as the proper notion of nine by subtracting unity, and similarly as the proper notion of each of the numbers included under it.

3) So, too, it can take in man the proper exemplar of irrational animal as such, and of each of its species, except that they would add some positive differences.

4) Thus, it is clear that, being absolutely perfect, the divine essence can be taken as the proper exemplar of singulars.

Tradução alemã de Albert, Allgaier et alii

1) Gott muss also, wenn er mehreres in seinem Eigensein erkennt, selbst das den einzelnen Dingen eigene Wesensbild sein.

2) Er kann nämlich die Zehn als das der Neun eigene Vorbild erfassen, indem er die Einheit abzieht, und ebenso als das den einzelnen darunter liegenden Zahlen eigene Vorbild. 
3) Ebenso kann er auch im Menschen das dem vernunftlosen Lebewesen als solchem und seinen einzelnen Arten eigene Urbild (...) erfassen.

4) Dabei ist offenbar, dass das Wesen Gottes, insofern es absolut vollkommen ist, als das den einzelnen Dingen eigene Vorbild verstanden werden kann.

Ao compararmos os diferentes textos, constatamos que os três tradutores não vertem de maneira uniforme: nas frases 2) e 3), singulorum e singularum são traduzidos corretamente, enquanto que as ocorrências de singulorum nas frases 1) e 4) são equivocadamente traduzidas por singuliers/singulars/einzelne Dingen. Daí resulta, assim nos parece, um contra-senso relativamente ao propósito de nosso autor ${ }^{35}$. Propósito esse que não é outro que mostrar como Deus, em virtude do conhecimento que possui de sua própria essência, possui um conhecimento próprio de cada uma das perfeições específicas que caracterizam o seu ato criador. Tomás não fala de coisas singulares. Não é possível apoiar-se no capítulo em questão para sustentar que Tomás defende que Deus possui as ideias próprias, quer dizer, distintas, de coisas singulares. A fortiori, não é possível usar o seu testemunho para afirmar que as ideias, segundo Tomás, são primeira ou principalmente ideias de coisas singulares.

d) Summa Theologiae, I, q. 15, a. 3

Passemos, enfim, ao último testemunho, a questão 15 , artigo 3 da Suma Teológica, prima pars. Trata-se de um artigo breve, no qual Tomás pergunta se Deus possui uma ideia correspondente a cada uma das coisas das quais ele possui conhecimento. $\mathrm{Na}$ medida em que Tomás considera a doutrina das ideias como sendo de origem platônica, é segundo os termos da doutrina de Platão, tal como Tomás é capaz de reconstitui-la, que o Aquinate busca responder a pergunta inicial. Considera-se que Platão tenha distinguido dois sentidos do termo "ideia": ideias enquanto princípio de conhecimento, e ideias enquanto princípio de geração. Responder a pergunta do artigo consiste, então, em determinar se Deus possui uma ideia de cada coisa de acordo com os dois sentidos propostos. A resposta de Tomás é afirmativa: há em Deus um princípio de fabricação de cada coisa (e, portanto, de coisas singulares), chamado "exemplar" (exemplar), e, também, um princípio pelo qual cada coisa é conhecida por Deus, chamado "noção" (ratio). ${ }^{36}$ Enquanto o primeiro faz referência ao 


\section{8}

aspecto prático do intelecto divino, o segundo refere-se ao seu lado especulativo. Embora Deus possua um conhecimento apenas especulativo dos possibilia, ele, por outro lado, tem também conhecimento prático de tudo aquilo que ele de fato vem a criar. No entanto, na medida em que não há, segundo Platão, ideias de gêneros, acidentes ou singulares ${ }^{37}$, não seria o caso de afirmar que o conhecimento, assim compreendido, se estende para além do campo das ideias, tomadas em sentido estrito?

Tomás trata desta questão na sua réplica à quarta objeção do artigo 3. A respeito das ideias de gêneros, ele afirma não poder haver ideias de gêneros que sejam distintas das ideias de espécies, já que os gêneros têm sua existência necessariamente vinculada à existência das espécies. Em seguida, Tomás distingue entre acidentes necessários e acidentes que sobrevêm ao sujeito (superveniunt subiecto): embora, no caso dos primeiros, não haja ideia que seja distinta da ideia do sujeito ao qual o acidente se refere, no caso dos acidentes supervenientes há necessidade de uma ideia distinta da do sujeito. E o que dizer das coisas singulares? Após sustentar não poder haver, segundo a ótica platônica, ideias de singulares que sejam distintas das ideias relativas a espécies, visto que o singular é individuado pela matéria, a qual, juntamente com a ideia, funciona como co-causa dos singulares, Tomás se limita a dizer que "a providência divina se estende tanto à espécie quanto ao indivíduo", remetendo o leitor, para maiores detalhes acerca do ponto, à questão 22, cujo tema é justamente a providência divina. ${ }^{38}$ Por sua vez, a análise da questão 22 nos faz descobrir que, lá, Tomás expõe os diferentes modos pelos quais Deus conhece os seres, incluindo aí os singulares, sem, no entanto, fazer menção à doutrina das ideias. ${ }^{39}$ Sua resposta termina com uma simples afirmação de princípio, sem apoiar-se em argumento algum.

\section{0 caso do Quodlibet 8, Q. 1, A. 2}

Nos resta ainda examinar uma última passagem. Trata-se de um texto das Questões Quodlibetais 8, q. 1, a. 2, que datam da primeira fase da obra tomásica (1256-59) ${ }^{40}$. O motivo pelo qual damos tratamento separado a este texto é que este é o único onde Tomás explicitamente levanta a questão de saber qual é o objeto de que trata a ideia: o singular ou a 
natureza específica ("utrum rationes quae sunt in mente divina per prius respiciant exemplata, scilicet creaturas, ratione suae singularitatis, vel ratione naturae specificae"). Como veremos, a doutrina exposta por Tomás no Quodlibet 8, q. 1, a. 2 se põe de acordo com o que já tivemos oportunidade de ver a respeito da doutrina do De Veritate.

A reposta do Aquinate está fundada na distinção entre a produção humana e a criação: um artesão trabalha uma matéria pré-existente, à qual ele confere uma forma, que não é outra que a espécie da coisa produzida. Deus, por sua vez, tanto cria a forma quanto a matéria dos entes. Sua atividade criadora não se restringe à confecção da forma, mas se estende à singularidade do ente criado. A atividade criadora divina, especifica Tomás "se refere, em primeira instância, à natureza da espécie" (per prius tamen quantum ad naturam speciei). E assim é, já que, segundo Tomás, a atividade de um agente se refere primordialmente ao que há de mais perfeito em sua produção. Ora, o que há de mais perfeito numa coisa é justamente a natureza de sua espécie, de modo que aquilo a que visa a natureza não é, em primeira instância, nem o indivíduo nem o gênero, mas a espécie. Não é a geração de Sócrates, mas a de homem que é objetivada - caso contrário, a intenção da natureza destruir-se-ia com o fenecimento de Sócrates. Tampouco é o animal que é visado: no processo da geração humana, a animalidade é adquirida antes da espécie; de modo que, fosse o gênero o fim almejado pela natureza, o processo terminaria quando da produção de animal. ${ }^{41}$

Ao sustentar que as ideias divinas são também ideias de indivíduos, Tomás confirma aquilo que ele havia dito alhures, embora aqui ele seja bem mais explícito quanto ao estatuto dos particulares em relação às ideias divinas. Quanto a este ponto, não resta dúvida: a ideia se refere ao indivíduo sob o aspecto de sua natureza específica. O que é mais, ao perguntar-se se as ideias divinas se referem prioritariamente às coisas sob o ângulo de sua individualidade ou sob o ângulo de sua especificidade, Tomás dá a entender que Deus não possui ideias distintas de indivíduos.

Tomás fornece mais detalhes sobre a sua posição ao responder a seguinte objeção: as ideias divinas são algo estável e eterno, a partir das quais são produzidas coisas corruptíveis; como o corruptível é singular, segue-se que as ideias se referem (respiciunt) primordialmente ao singular. Tomás responde recorrendo à máxima segundo a qual o que é anterior na ordem 
da intenção é posterior na ordem da realização: embora o que é produzido seja este homem, o que é almejado é a produção de (um) homem.

O texto do Quodlibet, como se viu, ao invés de assegurar uma relação privilegiada entre ideia e indivíduo, subordina a relação ideia-indivíduo à relação ideia-espécie. É evidente que uma tal conclusão não se ajusta com facilidade à interpretação dos comentadores. V. Boland, por exemplo, admite que Tomás não distingue, no texto do Quodlibet, a ideia referente ao gênero da ideia da coisa em que o gênero se realiza ("... there is no idea of a genus apart from a specific realisation of that genus" 42 ), mas ele lembra que este é um texto do jovem Tomás, e sustenta que a posição do autor evolui, citando em particular a resposta da questão 15, artigo 3 da Suma Teológica, onde Tomás estende a providência divina ao singular: "But in his maturer work he says that because God's providence extends to individual things there must be ideas of individuals and not just of species" 43 . No entanto, como já dissemos, quando Tomás trata do problema do conhecimento divino acerca do particular no contexto da doutrina da providência, ele procede sem fazer menção à doutrina das ideias. Além do mais, Tomás não esperou até a composição da Suma para afirmar que Deus conhece os singulares. A tese já se faz presente no De Veritate e em Sobre as Sentenças, que são, assim como o Quodlibet, obras de juventude.

G. Doolan, por sua vez, emprega toda a sua engenhosidade a fim de mostrar que a posição de Tomás no Quodlibet não é incompatível com a sua própria interpretação do De Veritate, q. 8, a. 2, onde Tomás sustentaria que as ideias divinas em sentido próprio são ideias de coisas singulares. Os dois textos harmonizar-se-iam, porque "Thomas does not ask whether ideas are properly of individuals but, rather, how the ideas are related to individuals" 44 . Sua estratégia, no entanto, soa como um artificio ad hoc. Em todo caso, o autor não cita nenhum texto em que Tomás atribua às locuções "ideia de coisa individual" (idea rei ; idea of an individual) e "ideia relativa a um indivíduo" (respicere rem; to be related to individuals) significados diferentes.

\section{Conclusão}

No presente artigo, buscamos apresentar a doutrina tomásica concernente ao problema das ideias de singulares a partir das principais 
passagens dedicadas por Tomás a este tema, desde a época de seu comentário às Sentenças até a Suma Teológica, fruto de sua maturidade intelectual. Passemos a um breve resumo dos principais pontos. Em Sobre as Sentenças, Tomás sustenta que Deus possui ideias de singulares, no entanto, tão logo ele explica em que sentido isto é verdadeiro, constatamos que coisas particulares correspondem de modo imperfeito a suas ideias. No De Veritate, Tomás é enfático no que diz respeito ao conhecimento de singulares, embora os detalhes de sua resposta não nos permitam distinguir entre a ideia de um singular e a ideia da espécie correspondente. Na Suma Contra Gentios, o capítulo que sempre prendeu a atenção dos eruditos, I, 54, não aborda a questão das "rationes" (noções) das coisas singulares, mas, antes, explora o tema do conhecimento das naturezas específicas. E se Tomás revisita, na Suma Teológica, o problema das ideias de singulares, é simplesmente para posicionar-se de maneira peremptória, remetendo o debate à questão da providência divina, onde procuramos, no entanto, em vão por uma explicação cabal. Enfim, no Quodlibet, cujo argumento central apresentamos em separado, Tomás enuncia sem rodeios o caráter derivado e secundário do indivíduo no respeitante à ideia divina, sem negar, no entanto, que as ideias, as quais se referem principalmente à especificidade da coisa, se relacionam de uma certa maneira às coisas singulares.

À luz destes diferentes textos, parece muito pouco razoável afirmar que, segundo Tomás, as ideias divinas são, em primeira instância, ideias de coisas particulares. Na medida em que Tomás admite que há ideias de coisas singulares, ele não parece distingui-las das ideias das espécies e dos gêneros sob os quais os singulares se incluem. E na medida em que é legítimo distinguir, no âmbito da coisa criada, a coisa enquanto singular, enquanto espécie, e enquanto gênero, Tomás indica claramente que a ideia divina se refere fundamentalmente à coisa enquanto espécie. O que dizer da primeira das duas interpretações que distinguimos na nossa introdução, a saber, aquela segundo a qual Tomás estaria a sustentar que Deus possui uma ideia especial para cada uma das coisas criadas? Esta é a tese defendida por M. Hoenen, que sustenta que "[b]y token of [God's knowledge of the things in his essence], each individual res has its rational form in God's mind"45. Mais uma vez, é preciso repetir que os textos não permitem afirmar que Tomás tenha efetuado com clareza a distinção 


\section{2}

entre ideia de particular e ideia de espécie. M. Hoenen menciona uma outra passagem para apoiar sua interpretação: ST I, q. 15, a. 2, ad 2, de modo que devemos atentar brevemente este texto.

O texto usado por Hoenen se encontra num artigo em que se trata da questão de saber se é conveniente postular uma pluralidade de ideias em Deus. Embora responda afirmativamente, Tomás precisa tratar da seguinte objeção: assim como a arte e a sabedoria divina, a ideia é um princípio de conhecimento, de modo que, assim como não há uma pluralidade de sabedorias, não é necessário falar-se em uma pluralidade de ideias. Tomás replica mediante uma distinção: enquanto a sabedoria é aquilo por que Deus conhece, a ideia é aquilo que ele conhece. O que chama a atenção na réplica de Tomás é o cuidado com o qual ele distingue entre inteligir uma coisa (singular) e ter a ideia desta mesma coisa; entre a coisa enquanto objeto e a intelecção da coisa enquanto objeto. Como de costume, Tomás ilustra o ponto com o exemplo do artesão: o artesão pode pensar a forma da casa que é inscrita na matéria, e, neste caso, é na casa concreta que ele pensa; ou ele pode pensar a forma da casa enquanto objeto de pensamento, que é o que ocorre quando ele considera a si mesmo ao pensá-la, e, neste caso, é na ideia ou "ratio" da casa que ele pensa. "Sicut artifex, dum intelligit formam domus in materia, dicitur intelligere domum, dum autem intelligit formam domus ut a se speculatam, ex eo quod intelligit se intelligere eam, intelligit ideam vel rationem domus. Deus autem non solum intelligit multas res per essentiam suam, sed etiam intelligit se intelligere multa per essentiam suam. Sed hoc est intelligere plures rationes rerum; vel, plures ideas esse in intellectu eius ut intellectas" 46 . Na medida em que Tomás distingue entre dois objetos de pensamento, a forma tal como ela existe na coisa extramental e a forma no intelecto, e como só a segunda é chamada de ideia, não é possível concluir que "cada coisa individual possui sua forma na mente divina”, como queria Hoenen, sem, ao menos, adicionar que, existindo na mente, ela deixa de ser diretamente singular.

Quando consideramos com que vigor Tomás defende o princípio de um conhecimento divino do singular, o conteúdo de sua argumentação no 
que concerne à questão das ideias divinas de singulares não deixa de surpreender. Como dar conta, em definitivo, de um tal contraste? A resposta reside em parte no fato que, tal como Tomás a compreende, a teoria das ideias foi concebida por Platão para explicar o aspecto formal e universal das coisas. De partida, então, a hipótese mesma de uma "ideia do singular" soa como um oxímoro. Em função de Tomás apegar-se a toda evidência em favor da tese que Deus possui ideias de singulares, e dado que a ideia enquanto tal não parece se referir, por definição, ao singular enquanto tal, Tomás se vê, assim, forçado, a fim de conciliar duas exigências contrárias, a situar a origem da singularidade da ideia nas coisas singulares elas mesmas. Em suma, o que singulariza uma ideia divina não é a ideia ela mesma, mas o objeto singular acerca do qual ela trata. A ideia jogaria perfeitamente o seu papel se a matéria, princípio de individuação, não entrasse em ação. Tomás admite isso, nessas mesmas palavras, num texto notável (ST I, q. 18, a. 4, ad 3), com o qual concluiremos nossa investigação. Se a matéria não fizesse parte da constituição dos entes físicos, "estes existiriam, segundo um modo sob todos os aspectos bem mais verdadeiro, nas ideias que estão na mente divina do que neles mesmos. É por isso que Platão defendeu que o homem separado é o homem verdadeiro, pois o homem material é homem por participação". O problema é justamente que a matéria entra na definição das coisas. Ao mesmo tempo, a ideia não tem mais nenhum papel a jogar na explicação de Tomás, de modo que ele não mais a menciona no resto de sua exposição. Ele prossegue, assim, afirmando que os entes fisicos possuem um ser (esse) mais verdadeiro na mente divina do que em si mesmos, visto que o seu ser em Deus corresponde ao ser de um ente incriado, embora eles possuam mais verdadeiramente este ou aquele ser em suas próprias naturezas. ${ }^{47}$

Como dissemos na abertura deste trabalho, Tomás sempre defendeu a tese que Deus possui conhecimento dos singulares. Sua doutrina da providência, a qual implica que cada homem seja objeto de uma solicitude especial, a impõe. Seu aristotelismo arraigado naturalmente o inclina a ela. Mas a doutrina das ideias, sob cuja luz ele é levado, assim como todos os seus contemporâneos, a tratar do problema do conhecimento de singulares, tem limites muito exíguos, tolhendo, assim, a plena expansão de seu "aristotelismo ontológico". Foi isso o que buscamos sugerir ao longo do nosso artigo. 


\section{4}

1 No presente artigo, consideramos equivalentes as expressões "coisas singulares" e "coisas particulares", sem prejulgar eventuais nuances de sentido que estas possam comportar. Todas as citações de Tomás são feitas segundo a edição numérica do Corpus Thomisticum, acessível pelo sítio http://www.corpusthomisticum.org/.

${ }^{2}$ Ver Hoenen, 1993, p. 123: "Considering his argument for the existence of ideas, we may presume that the practical aspect of ideas was more important for Thomas. Of whatever can be an independent object of his creative activity, God has practical ideas. This goes for particulars, of course, but it is also true of species, because nature inclines toward the preservation of the species". O autor resume sua posição duas páginas adiante (p. 125) da seguinte maneira: "The position of Thomas Aquinas, as we have seen, was that God had practical ideas of each particular". Na mesma esteira, Doolan, 2008, p. 127: "Since ideas taken in the strict sense do belong to practical knowledge, there are properly speaking only ideas of individuals because only individual things can actually be produced".

3 Jordan,1984, p. 24.

4 "No clearer statement of his (sc. de Tomás) acceptance of radical Aristotelian ontology is possible", Boland,1996, p. 226.

5 "Here, then, we see one of Thomas's significant departures from the Platonic tradition: according to the strict sense that he has outlined, divine ideas are not properly of universals but of individually existing things". Doolan, 2008 p. 144.

${ }^{6}$ A propósito da importância do contexto, ver os comentários de Beckmann, 1975. Há ainda um terceiro contexto, da providência divina, do qual trataremos apenas superficialmente.

7 Tomás não faz menção aos filósofos árabes no capítulo 65 de Contra Gentiles, o qual trata especificamente do conhecimento divino de singulares.

8 "Unde, cum ars divina sit productiva non solum formae, sed materiae, in arte sua non solum existit similitudo formae, sed materiae; et ideo cognoscit res et quantum ad formam et quantum ad materiam; unde non solum universalia sed et singularia cognoscit”. De ver., q. 2, a. 5, c.

9 "Cuius ratio manifeste apparet, si consideretur diversa habitudo quam habent ad rem similitudo rei quae est in intellectu nostro, et similitudo rei quae est in intellectu divino. Illa enim quae est in intellectu nostro, est accepta a re secundum quod res agit in intellectum nostrum, agendo per prius in sensum; materia autem, propter debilitatem sui esse, quia est in potentia ens tantum, non potest esse principium agendi; et ideo res quae agit in animam nostram, agit solum per formam. Unde similitudo rei quae imprimitur in sensum nostrum, et per quosdam gradus depurata, usque ad intellectum pertingit, est tantum similitudo formae. Sed similitudo rerum quae est in intellectu divino, est factiva rei (...)”. De ver., q. 2, a. 5, c.

10 Super Sent., d. 36, q. 2, a. 3, c.

11 Super Sent., lib. 1, d. 36, q. 2, a. 3, ad 3.

12 A ausência de semelhança entre um quadro e o sujeito que o quadro representa é uma propriedade compartilhada por ambos. Dito de outra maneira, a dessemelhança é uma propriedade simétrica.

13 "Nos autem ponimus Deum causam esse singularis et quantum ad formam et quantum ad materiam. Ponimus etiam, quod per divinam providentiam definiuntur omnia singularia; et ideo oportet nos

doispontos, Curitiba, São Carlos, vol. 7, n. 1, p.41-68, abril, 2010 
etiam singularium ponere ideas”. De Ver., q. 3, a. 8, c. (Nossa ênfase.)

14 " Ad secundum dicendum, quod si loquamur de idea proprie, secundum quod est rei, eo modo quo est in esse producibilis; sic una idea respondet singulari, speciei, et generi, individuatis in ipso singulari, eo quod Socrates, homo et animal non distinguuntur secundum esse. Si autem accipiamus ideam communiter pro similitudine vel ratione, sic, cum diversa sit consideratio Socratis ut Socrates est, et ut homo est, et ut est animal, respondebunt ei secundum hoc plures ideae vel similitudines". De Ver., q. 3, a. 8, ad 2.

15 Doolan, 2008, p. 127.

16 A ênfase é nossa.

17 Doolan escreve:"Indeed in his sed contra Thomas suggests that individual things have more of a need for distinct ideas than do universals", p. 125. É evidentemente problemático, porém, estabelecer uma interpretação sobre a frágil base de um sed contra. Sobre isso, ver Chenu, 1954, p. 80.

18 Doolan, 2008, p. 144 (ênfase do próprio autor).

19 Consultar Gauthier,1961.

20 Cf. Geiger, 1963.

21 Os textos suprimidos do capítulo 54 são reproduzidos na edição leonina da Suma: Sancti

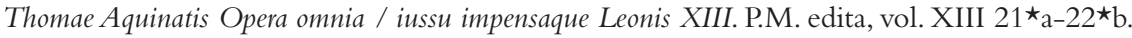

22 Consultar Boland, op. cit., p. 224-225 para uma possível explicação deste desaparecimento do termo na segunda redação.

23 Geiger, art. cit., p. 203.

24 De ver., q. 3, a. 3.

25 Contra Gentiles, I, 50, n. 1, nossa ênfase.

26 Ibid., I, 50, n. 3. Nossa ênfase.

27 Ibid., I, 50, n. 8. Nossa ênfase.

28 Ibid., I, 50, n. 9.

29 Ibid., I, 53, n. 5.

${ }^{30}$ Ibid., I, 54, n. 1.

31 Ibid., I, 54, n. 3.

32 Ibid.

33 Boland, 1996, p. 222. A ênfase é do próprio autor.

34 Doolan, 2008, p. 96. Nossa ênfase.

35 A antiga tradução francesa de Bernier e Corvez traduz de maneira fiel o texto do Aquinate:

1) Si donc Dieu possède une connaissance propre de choses nombreuses, c'est qu'il est lui-même la raison propre de chacune d'entre elles.

2) Il peut, par exemple, saisir la dizaine comme la raison propre de chacun des nombres que renferme cette dizaine.

doispontos, Curitiba, São Carlos, vol. 7, n. 1, p.41-68, abril, 2010 
3) De même encore, l'intellect peut appréhender dans l'homme l'exemplaire propre de l'animal non raisonnable en tant que tel et chacune de ses espèces.

4) Il est donc évident que l'essence divine, en tant qu'elle absolument parfaite, peut être considérée comme la raison propre de toute chose...

36 "Respondeo dicendum quod, cum ideae a Platone ponerentur principia cognitionis rerum et generationis ipsarum, ad utrumque se habet idea, prout in mente divina ponitur. Et secundum quod est principium factionis rerum, exemplar dici potest, et ad practicam cognitionem pertinet. Secundum autem quod principium cognoscitivum est, proprie dicitur ratio; et potest etiam ad scientiam speculativam pertinere. Secundum ergo quod exemplar est, secundum hoc se habet ad omnia quae a Deo fiunt secundum aliquod tempus. Secundum vero quod principium cognoscitivum est, se habet ad omnia quae cognoscuntur a Deo, etiam si nullo tempore fiant; et ad omnia quae a Deo cognoscuntur secundum propriam rationem, et secundum quod cognoscuntur ab ipso per modum speculationis.” Suma Teológica, I, q. 15, a. 3, c.

37 “Praeterea, constat quod Deus scit non solum species, sed etiam genera et singularia et accidentia. Sed horum non sunt ideae, secundum positionem Platonis, qui primus ideas introduxit, ut dicit Augustinus. Non ergo omnium cognitorum a Deo sunt ideae in ipso.” Suma Teológica, I, q. 15, a. 3, arg. 4.

38 "Ad quartum dicendum quod genera non possunt habere ideam aliam ab idea speciei, secundum quod idea significat exemplar, quia nunquam genus fit nisi in aliqua specie. Similiter etiam est de accidentibus quae inseparabiliter concomitantur subiectum, quia haec simul fiunt cum subiecto. Accidentia autem quae superveniunt subiecto, specialem ideam habent. Artifex enim per formam domus facit omnia accidentia quae a principio concomitantur domum, sed ea quae superveniunt domui iam factae, ut picturae vel aliquid aliud, facit per aliquam aliam formam. Individua vero, secundum Platonem, non habebant aliam ideam quam ideam speciei, tum quia singularia individuantur per materiam, quam ponebat esse increatam, ut quidam dicunt, et concausam ideae; tum quia intentio naturae consistit in speciebus, nec particularia producit, nisi ut in eis species salventur. Sed providentia divina non solum se extendit ad species, sed ad singularia, ut infra [sc. q. 22, a. 2.] dicetur”. Suma Teológica, I, q. 15, a. 3, ad 4.

39 Cf. "Cum autem Deus sit causa rerum per suum intellectum, et sic cuiuslibet sui effectus oportet rationem in ipso praeexistere, ut ex superioribus patet; necesse est quod ratio ordinis rerum in finem in mente divina praeexistat." Suma Teológica, I, q. 22, a. 1, c.; "Similiter etiam supra ostensum est quod Deus omnia cognoscit, et universalia et particularia. Et cum cognitio eius comparetur ad res sicut cognitio artis ad artificiata, ut supra dictum est, necesse est quod omnia supponantur suo ordini, sicut omnia artificiata subduntur ordini artis." Ibid., a. 2, c.; "Quia in suo intellectu habet rationem omnium, etiam minimorum", ibid., a. 3, c.

40 Cf. Torrell, 1993, p. 492.

41 "Respondeo. Dicendum, quod, cum in mente divina sint omnium creaturarum formae exemplares, quae ideae dicuntur, sicut in mente artificis formae artificiatorum; hoc tamen interest inter formas exemplares quae sunt in mente divina et in mente artificis creati: quod creatus artifex agit ex praesupposita materia; unde formae exemplares quae sunt in mente eius, non sunt factivae materiae, quae est individuationis principium, sed solius formae, a qua est species artificiati: et ideo huius formae exemplares non respiciunt directe artificiatum quantum ad individuum, sed quantum ad speciem solum; formae autem exemplares intellectus divini sunt factivae totius rei et quantum ad formam et quantum ad materiam: et ideo respiciunt creaturam non solum quantum ad naturam speciei, sed etiam quantum ad singularitatem individui: per prius tamen quantum ad naturam speciei: quod ex hoc patet. Exemplar enim est ad cuius imitationem fit aliquid. Unde ad rationem exemplaris requiritur quod ipsa assimilatio operis ad exem-

doispontos, Curitiba, São Carlos, vol. 7, n. 1, p.41-68, abril, 2010 
plar sit intenta ab agente: alias talis assimilatio casu accideret, et non secundum viam exemplaritatis. Sic ergo in ratione exemplaris, includitur intentio agentis. Ad hoc ergo per prius exemplar respicit quod agens primo intendit in opere. Agens autem quilibet principaliter intendit in opere id quod perfectius est. Natura autem speciei est perfectissimum in unoquoque individuo". QuodlibetVIII, q. 1, a. 2, c.

42 Boland, 1996, p. 227.

43 Ibid.

44 Doolan, 2008, p. 129.

${ }^{45}$ Ver Hoenen, 1993, p. 122.

46 Suma Teológica, I, q. 15, a. 2, ad 2.

47 Suma Teológica, I, q. 18, a. 4, ad 3: “Ad tertium dicendum quod, si de ratione rerum naturalium non esset materia, sed tantum forma, omnibus modis veriori modo essent res naturales in mente divina per suas ideas, quam in seipsis. Propter quod et Plato posuit quod homo separatus erat verus homo, homo autem materialis est homo per participationem. Sed quia de ratione rerum naturalium est materia, dicendum quod res naturales verius esse habent simpliciter in mente divina, quam in seipsis, quia in mente divina habent esse increatum, in seipsis autem esse creatum. Sed esse hoc, utpote homo vel equus, verius habent in propria natura quam in mente divina, quia ad veritatem hominis pertinet esse materiale, quod non habent in mente divina. Sicut domus nobilius esse habet in mente artificis, quam in materia, sed tamen verius dicitur domus quae est in materia, quam quae est in mente; quia haec est domus in actu, illa autem domus in potentia".

\section{Referências bibliográficas}

BECKMANN, J. 1975. "Der ideentheoretische Grundansatz bei Thomas v. Aquin, Duns Scotus und Wilhelm v. Ockham". Tommaso d'Aquino nella storia del pensiero, Napoli: Edizioni Domenicane Italiane, Atti del Congresso internazionale (Roma-Napoli, 17-24 aprile 1974) Tommaso d'Aquino nel suo settimo centenario, v. 1, p. 287.

BOLAND, V. 1996. Ideas in God according to Saint Thomas Aquinas. "Studies in the History of Christian Thought", vol. 69. Leiden: Brill.

CHENU, M.-D. 1954. Introduction à l'étude de saint Thomas d'Aquin. Montréal: Institut d'études médiévales; Paris:Vrin.

DOOLAN, G. 2008. Aquinas on the Divine Ideas as Exemplar Causes. Washington (D.C.): The Catholic University of America Press.

GAUTHIER, R.-A. 1961. "Introduction historique”. In: Bernier, R. \& Corvez, M. Somme contre les Gentils: livre I. Paris: Lethielleux, p. 7-59. 
GEIGER, L.-B. 1963. "Les rédactions successives de contra gentiles I, 53 d'après l'autographe", Saint Thomas d'Aquin aujourd'hui, "Recherches de philosophie", 6. Paris: Desclée de Brouwer, p. 221240 .

HOENEN, M. 1993. Marsilius of Inghen: Divine Knowledge in late Medieval Thought. "Studies in the History of Christian Thought", vol. 50. Leiden: Brill.

JORDAN, M. 1984. "The Intelligibility of the World and the Divine Ideas in Aquinas" Review of Metaphysics, 38:1, p. 17-32.

TOMÁS DE AQUINO. 1882. S. Thomae Aquinatis Doctoris Angelici Opera Omnia. Roma: Comissio Leonina. 1955. Summa Contra Gentiles: Book 1: God. Translated with Introduction and Notes by Anton C. Pegis. Notre Dame (IN): University of Notre Dame Press. .1961. Somme contre les Gentils I. Traduction par Bernier, R. et Corvez, M. Paris: Lethielleux. 1999. Somme contre les Gentils I. Présentation et Traduction par Cyrille Michon. Paris: GF Flammarion. 2009. Thomas Aquinatis Summae contra gentiles libri quattuor. Herausgegeben, übersetzt und mit Anmerkungen versehen von K. Albert, K. Allgaier et alii, Darmstadt:WGB.

TORRELL, J.-P. 1993. Initiation à saint Thomas d'Aquin: Sa personne et son cuvre. Paris: Cerf; Fribourg: Éditions universitaires. 